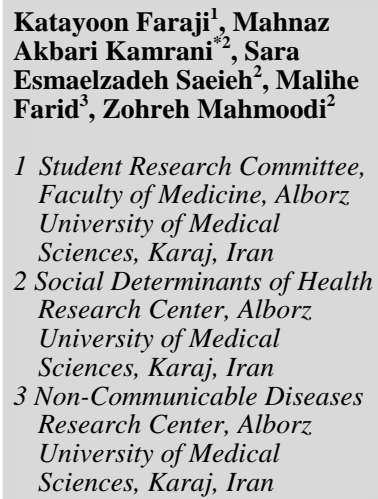

1 Student Research Committee, Faculty of Medicine, Alborz University of Medical Sciences, Karaj, Iran

2 Social Determinants of Health Research Center, Alborz University of Medical Sciences, Karaj, Iran

3 Non-Communicable Diseases Research Center, Alborz University of Medical Sciences, Karaj, Iran

*Corresponding Author: Social Determinants of Health Research Center, Alborz University of Medical Sciences, Karaj, Iran

Tel: $026-34643254$

E-mail: akbarikamrani21@gmail.com

\section{Self-Care Consulting on Women's Screening Behavior During Perimenopause in Karaj, 2016}

Received:12 Sept. 2017 ; Accepted:23 Oct. 2017

\section{Abstract}

Background: Promoting health and providing a sense of well-being in any woman's life cycle would improve quality of life and bring great benefits to a community. Lifelong change and increased life expectancy have led women to spend more years in postmenopausal women. In this research, self-care consulting on women's screening behavior during perimenopause has been investigated.

Methods: The samples of this quasi-experimental study were 42 eligible women from 3951 years who were selected by convenience sampling. Data collection tools included demographic questionnaire and perimenopause self-care researcher-made questionnaire. Screening behavior change was measured before, one month and three months after consulting. This study was approved by the Ethics Committee of Alborz University of Medical Sciences (Abzums.Rec.1395, 12). SPSS v19 was used to analyze the data.

Results: Friedman non- parametric test showed that screening counseling behavior of participants increased significantly after one and three months after self-care counseling $(p<0.0001)$.

Conclusion: The results of this study suggest the effectiveness of a health behavior change counseling designed based on individual self-care levels.

Keywords: Self-care, Consulting, Screening behavior 


\section{" بر رسى تاثير مشاوره مبتنى بر خودمراقبتى بر رفتار غربالكرى ومشاورهاى زنان كرج درحول و حوش يائسكى}

تاريخ دريافت مقاله؛ 99/9/Y ؛ تاريخ بذيرش:

حكکب:

مقدمه: ارتقاى سلامتى و فراهم نمودن احساس خوب بودن در هر يك از دورههاى زندكى يكى زن، بهبودكيفيت زندكى را براى او رقم زده و ثمرات زيادى براى يكى جامعه به بار خواهد آورد. تغيير در طول عمر و افزايش اميد به زنـدكى باعـث شده است كه زنان سالهاى بيشترى را در دوران بعد از يائسكى سيرى كنند . پيزوهش حاضر به بررسى تاثير مشاوره مبتنى بر خودمراقبتى بر رفتار غربالخرى ومشاورهاى زنان حول وحوش يائسخى يرداخته است.

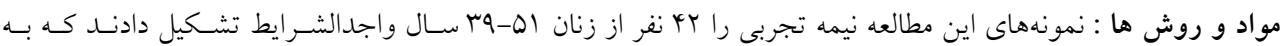
صورت نمونه گيرى دردسترس انتخاب شدند. ابزار گردآورى دادهها شامل تيرسش نامـه دموگر افيـك و يرسشـنامه محقـق ساخته خود مراقبى زنان حول وحوش يائسخى انجام شد. تغيير رفتار غربالكرى قبل، يك و سه ماه يس از مشاوره سنجيده شد. اين تُزوهش مورد تائيد كميته اخلاق دانشخاه علوم يزشكى البرز قرار گرفته است(Abzums.Rec.1395، 12). دادههـا با استفاده از نرم افزار 19 spss مورد تجزيه و تحليل قرار كرفت. يافته ها: نتايج آزمون نان يارامتريك فريدمن نشان داد رفتارغربالكرى ومشاورهاى زنان در حول و يائسكى يك و سـه مـاه

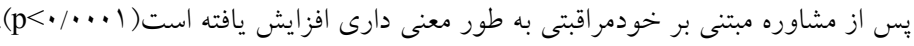
نتيجه گيرى: نتايج اين مطالعه اثربخشى مشاوره تغيير رفتار بهاشتى را كه با تكيه بر سـطح خـودمراقبتى هـر فـرد طراحسى كرديده است بارزتر مىنمايد. كلمات كليدى: خودمراقبتى، مشاوره، حول وحوش يائسكى

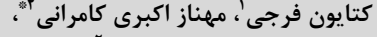

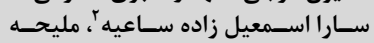
فريد"، زهره محمودى إديـ

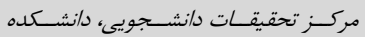

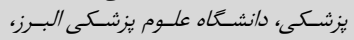
كرج، ايران

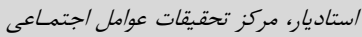

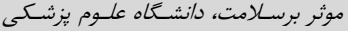
البرز، كرج، ايران

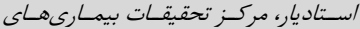

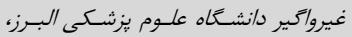
كرج،/يران

$$
\text { ب. }
$$


بهداشت بالاتر اين دوره به بيش از ·• سال نيز رسيده اسـتو ايسن

در حالى است كه سن يائسخى تغير نكرده است.

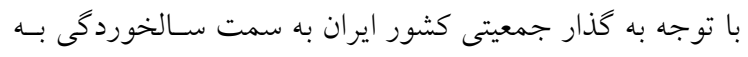
نظر مىرسد توجه به سلامتى اين گـروه سـنى مسى توانــ كـامى در

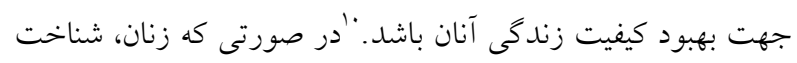
كافى نسبت به علائم دوران يائسكى داشته باشند، عوارض ناشسى از

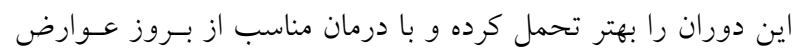

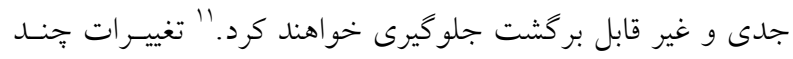

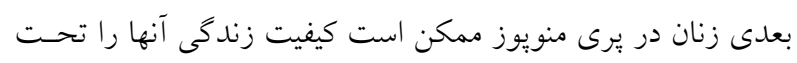

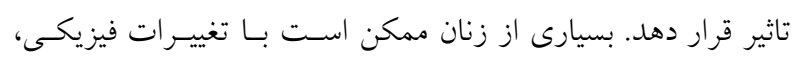

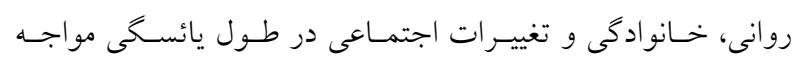

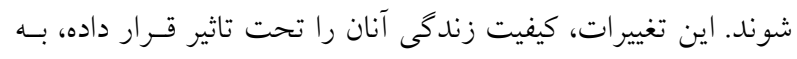

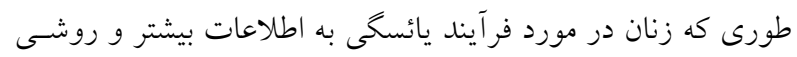

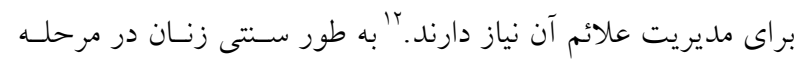

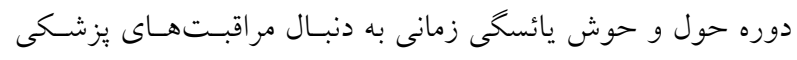

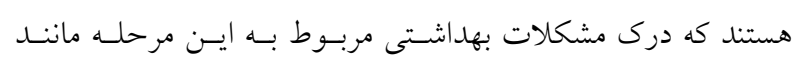

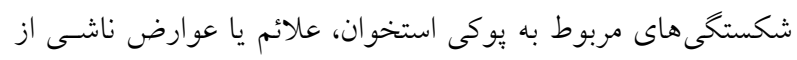

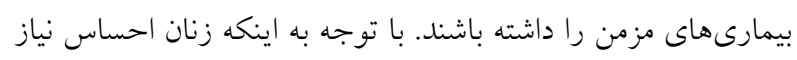

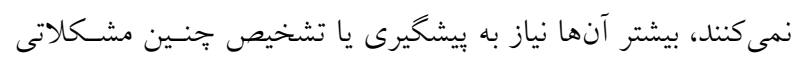

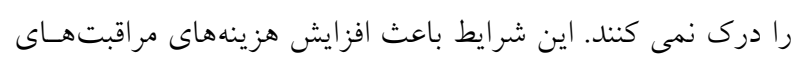

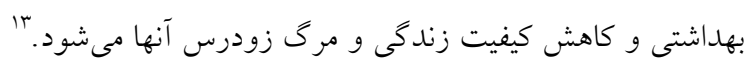

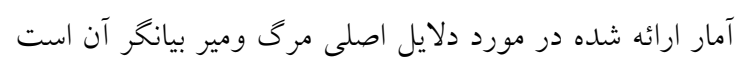

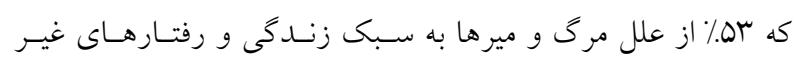

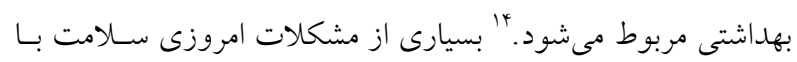

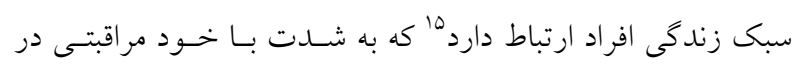
ارتباط مىباشد. خود مراقبتى به معنى فرآيند حفظ سلامتى از طريق

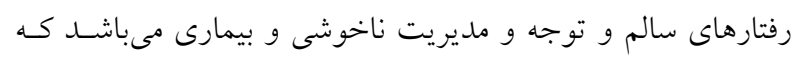

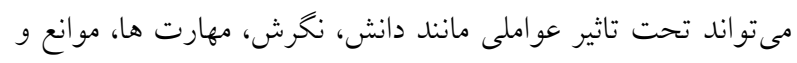

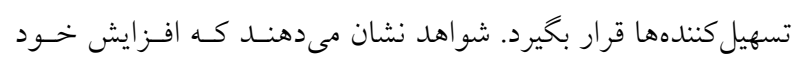

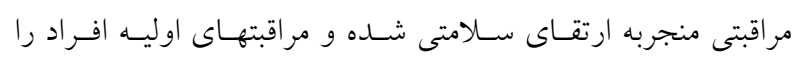

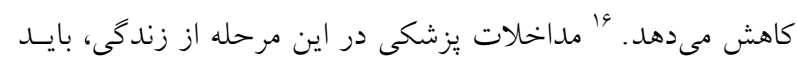

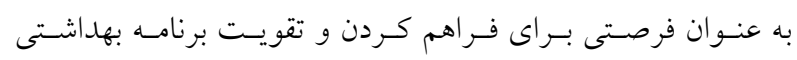

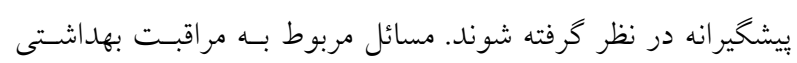

سلامت زنان يكى از محور ها و شاخص هاى توسعه مىباشـــ و

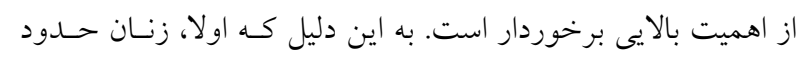

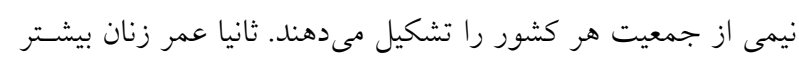

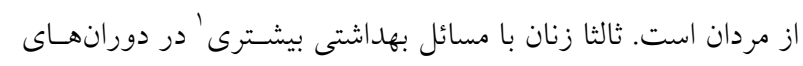
مختلف زندگى از جمله بلوغ، حاملكى، زايمان، شيردهى و بـالاخره

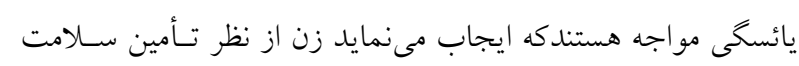

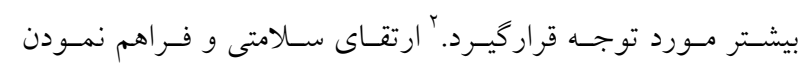

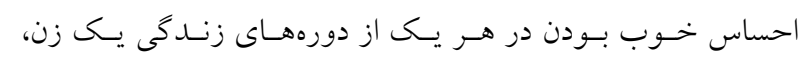

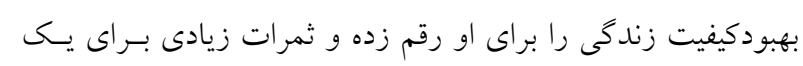
جامعه به بار خواهد آورد.' دوره كذر از يائسكى با افزايش ميزان هورمون محركه فوليكولى بارد

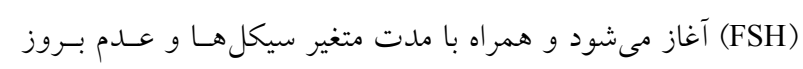
قاعدگى در برخى از سيكل ها مشخص و با آخــرين قاعـدكى بايـان

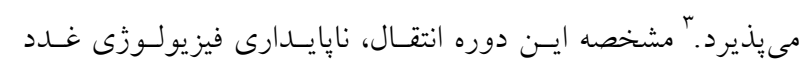

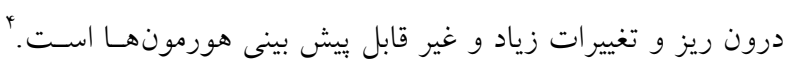

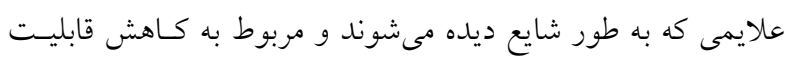

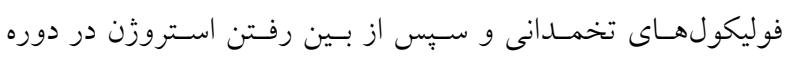

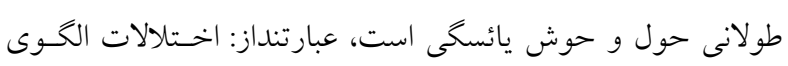

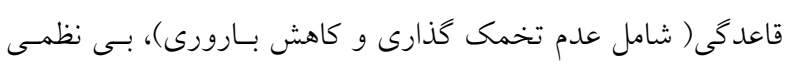

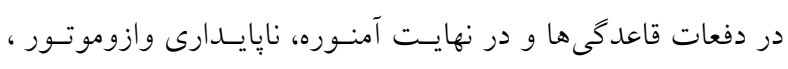

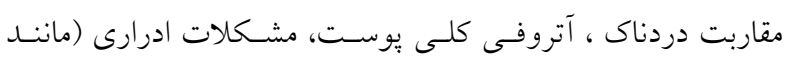

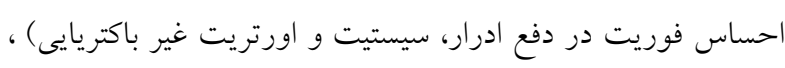
مشكلات بهداشتى ناشى از محروميت دراز مدت از استروزن (نظيـر

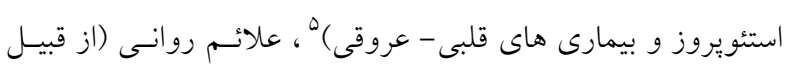

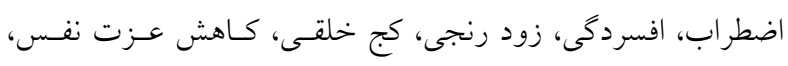

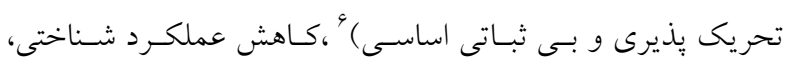

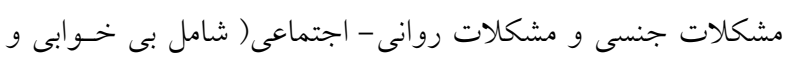
خستخى، كاهش تمركز و فراموشى) مى باشد.'

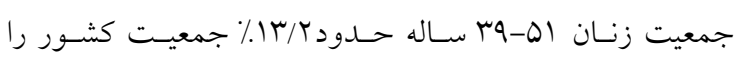

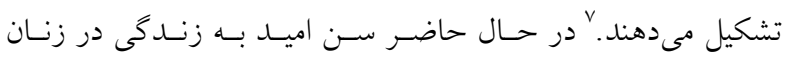

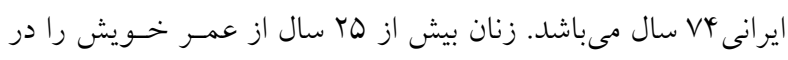

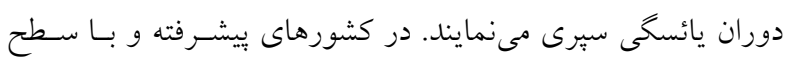




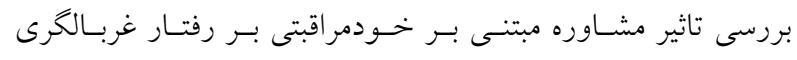

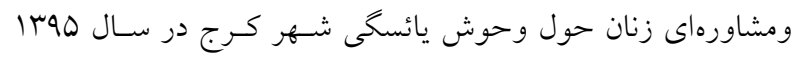
انجام شد.

\section{مواد وروشها}

مطالعه حاضر از نوع نيمه تجربى قبل و بعـــ از مداخلـه اسـت.

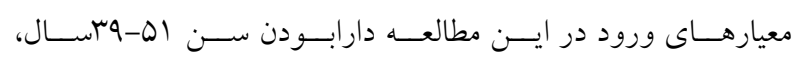

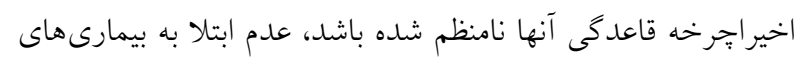

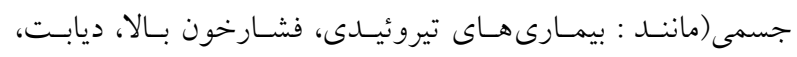

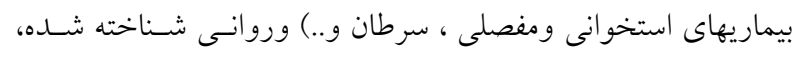

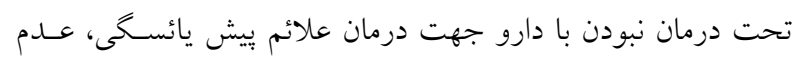

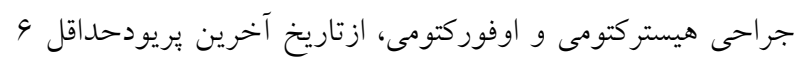

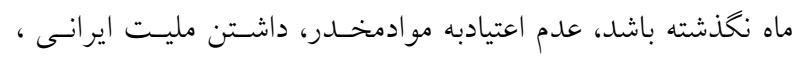

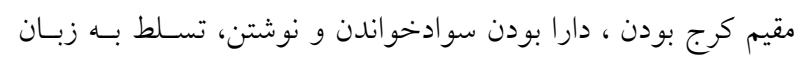

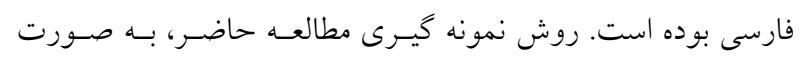

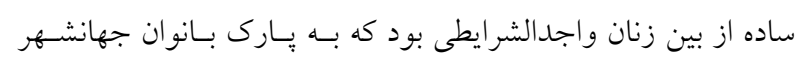

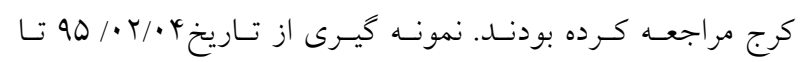

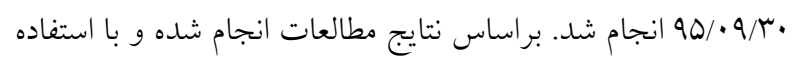

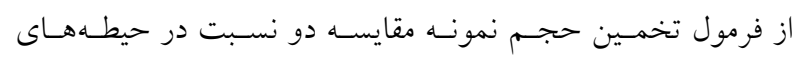

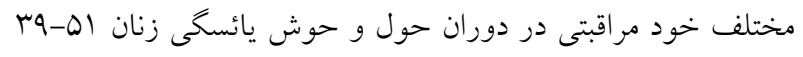
سال، حجم نمونه اين يزوهش بَ بن نفر تخمين زده شد.

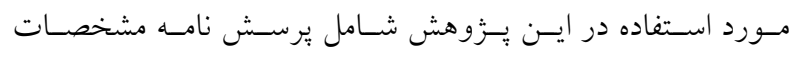

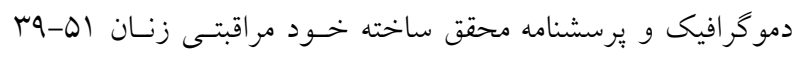

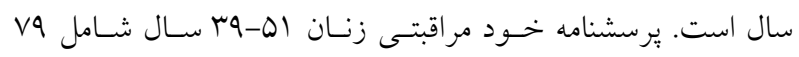

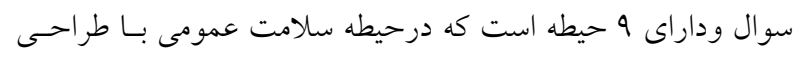

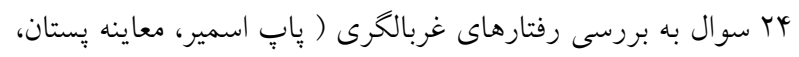

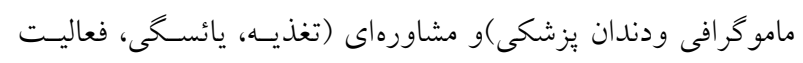

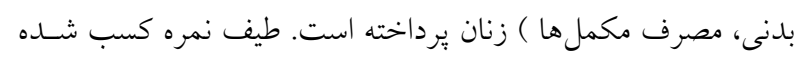

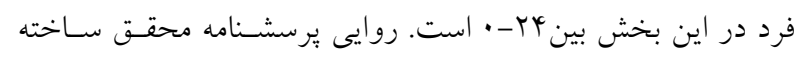

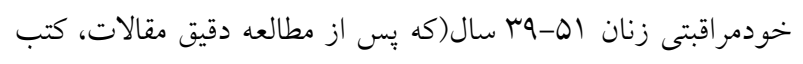

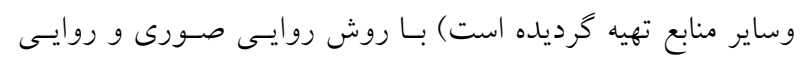

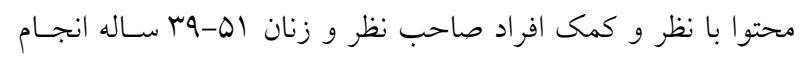

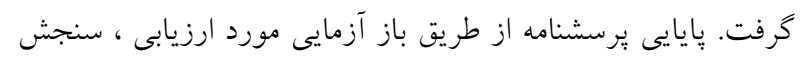

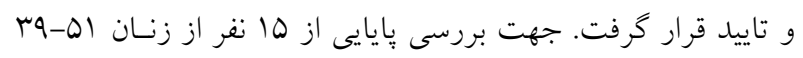

يبشخير انه از زنان، موضوعات آشنايى هستند. اين مسائل شامل قطع

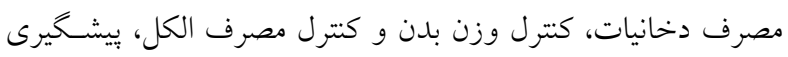

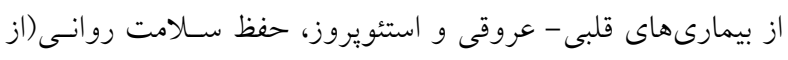

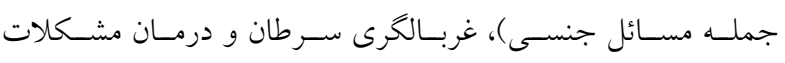

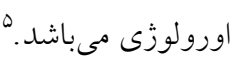

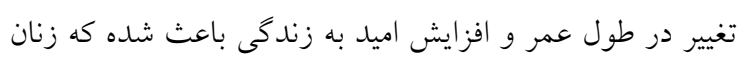

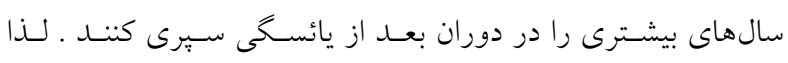

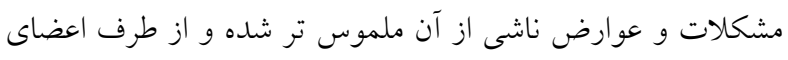

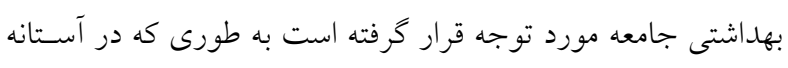

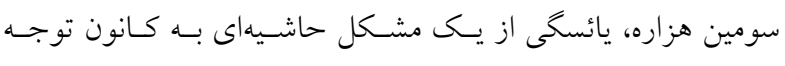

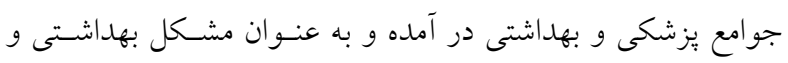

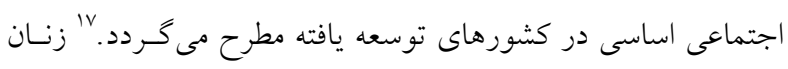

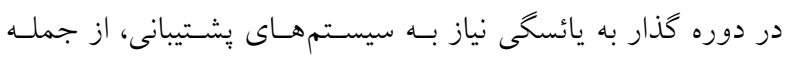

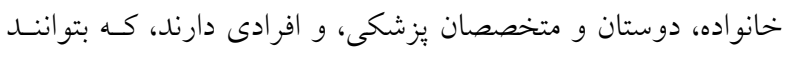

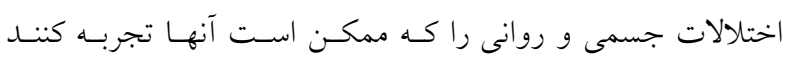

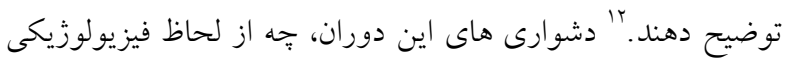

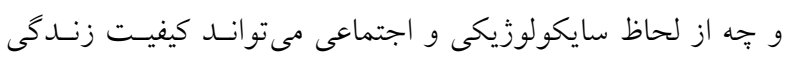

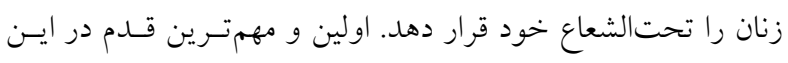

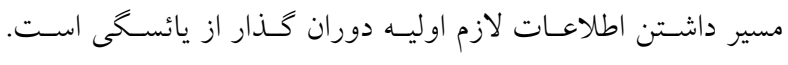

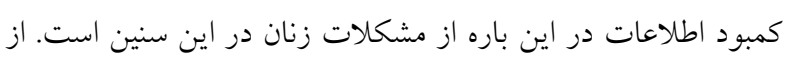

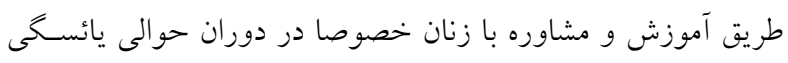

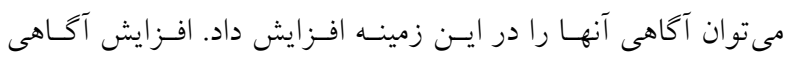

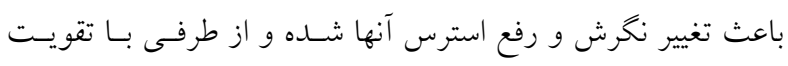

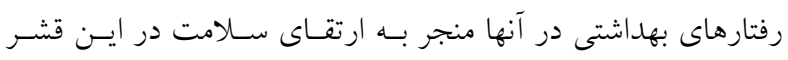
مى كردد. تحقق جامعه سالم در كـرو سـلامت زنـان، مـادران و دختـــــان

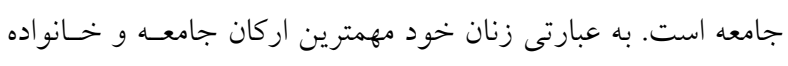

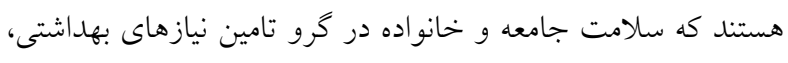

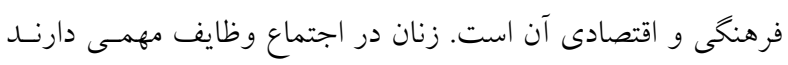

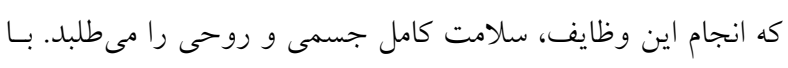

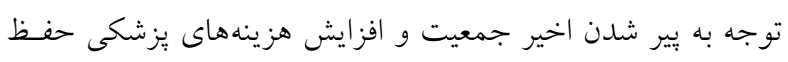

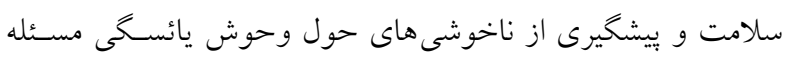

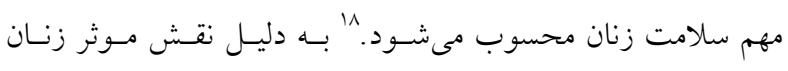

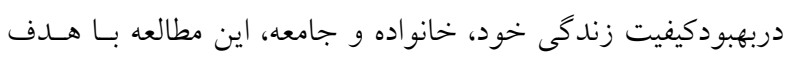


حوش يائسكى توسط بزوهشكر تهيـه و از جلسـه دوم مشـاوره در

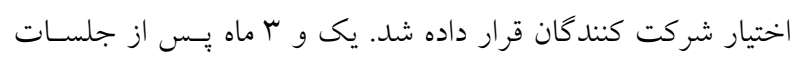
مشاوره مجددا يرسشناهه توسط شركت كنندكان تكميل شد.

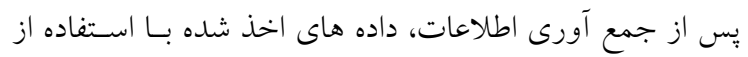

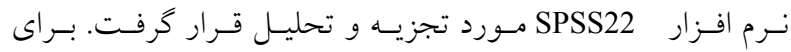

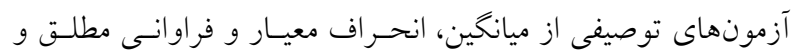

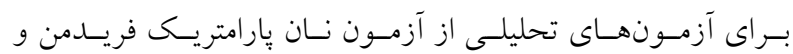

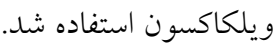

\section{يافته ها}

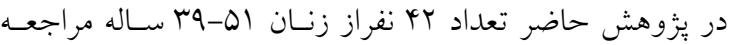

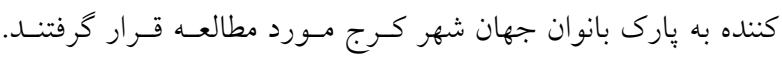

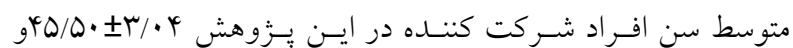

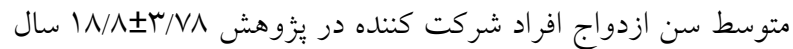

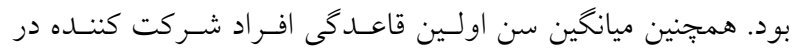

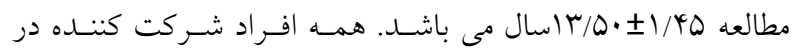

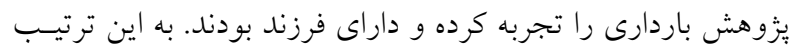

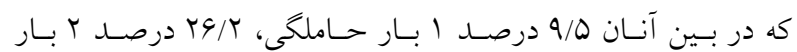

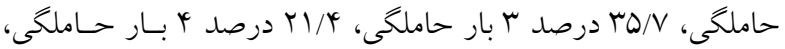

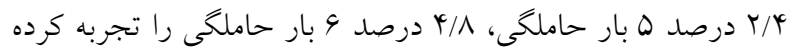
بودند. اكثريت افراد شركت كننده در يُوهش به ميزان 9V/9٪ تحت

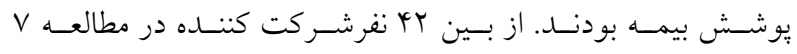

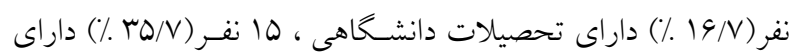
تحصيلات دييلم و مابقى شـركت كنـــان داراى تحصـيلات زيــر

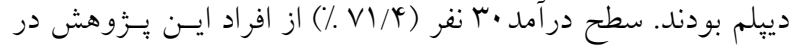

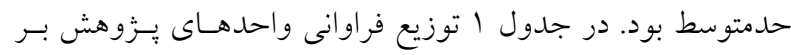

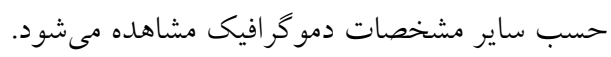

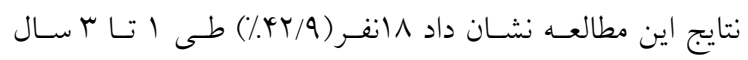

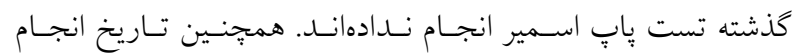

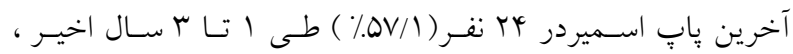

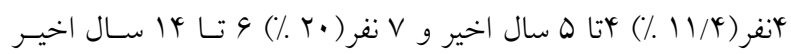

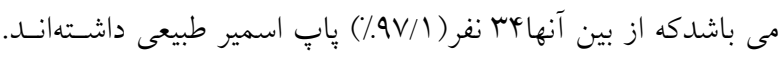

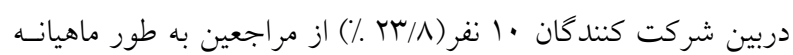
سينهاى خود را معاينه مى كنند.
ساله خواسته شد تا دو نوبت به فاصله • اروز ير سشــنامه را تكميـل

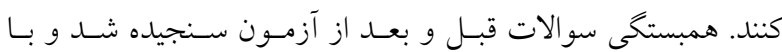

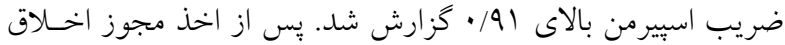

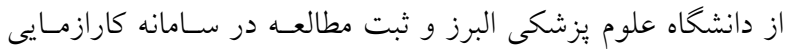
بالينى با كد (IRCT2016042427557N1) و انجام هماهنكى لازم بـا

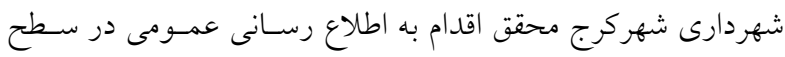

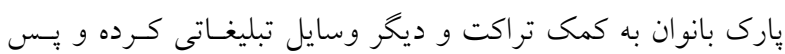

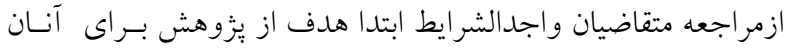
شرح داده شد و بِ ازكسـب رضـايت آكاهانـه از آنـان و تكميـل

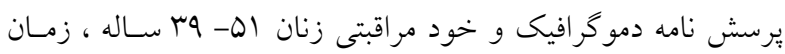

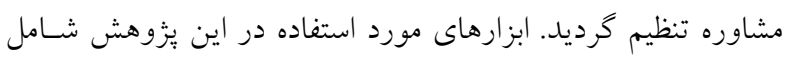
يرسش نامه مشخصات دموكرافيك و يرسشنامه محقق ساخته خـود

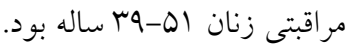
محتوا و هم جنين تعداد جلسات مشاوره براساس مشاوره رفتار بهداشتى (A) مبنى بر خودمراقبتى انجام كرفت. مشـاوره توسط آنسا

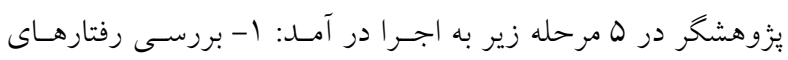

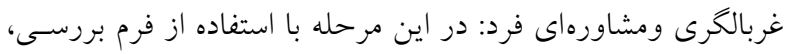
نمره خودمراقبتى فرد مورد بررسى قرار كرفت. در حقيقـت در ايسن فردئ

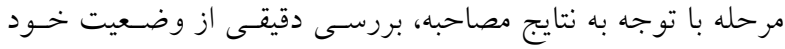

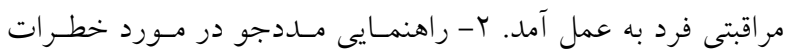

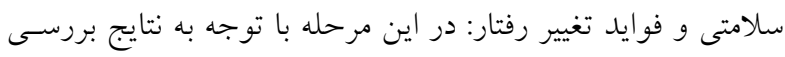
هاى مر حله قبل، موارد غير طبيعى تشخيص داده شده به اطلاع فـرد رسيد. خطرات سلامتى شناسايى شده در هر يـك از افـراد بــه آنها

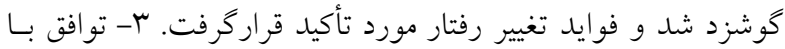

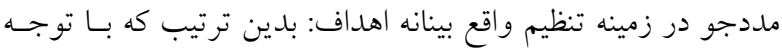

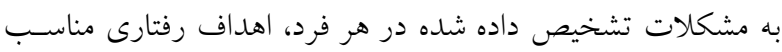
و مورد توافق تعيين و براى هريك از اهداف، برنامه عملى طر احسى دردي

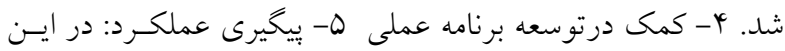

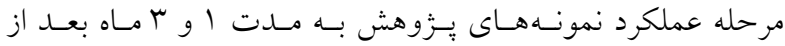

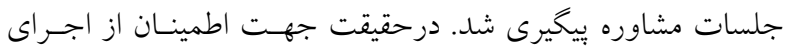
برنامه هاى عملى توسط واحدهاى يزوهش، تماس تلفنسى و بيامــ

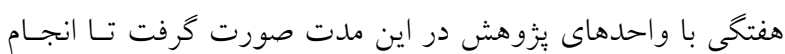
برنامه عملى يادآورى شود.

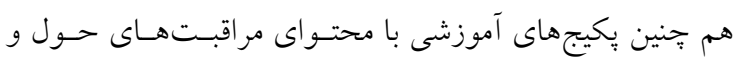




\begin{tabular}{|c|c|c|c|}
\hline درصد فراوانى & فراوانى & & متغير \\
\hline$M N / 1$ & $r v$ & خانه دار & وضعيت اشتغال \\
\hline $11 / 9$ & 01 & شاغل & \\
\hline $4 / 9$ & r & بيكار & شغل مراجع \\
\hline $9 N / r$ & $r \wedge$ & شاغل & \\
\hline rG/A & 11 & بازنشسته & \\
\hline$r Q / T$ & 19 & فارس & قوميت \\
\hline$Y Q / T$ & 19 & ترى & \\
\hline$r / Y$ & 1 & كرد & \\
\hline$T / Y$ & 1 & لر & \\
\hline$\varphi / \Lambda$ & r & غيره & \\
\hline Q. & r & بايه & نوع بيمه \\
\hline$Y V / q$ & $r$. & پايه و تكميلى & \\
\hline$r / T^{c}$ & 1 & هيجكدام & \\
\hline
\end{tabular}

نتايج ميانخين رتبه نمره خودمر اقبتى در حيطـه سـلامت عمـومى در اين آزمون مشخص مى نمايد كه بيشترين تغيير ميزان خودمر اقبتى در

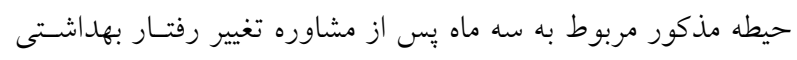

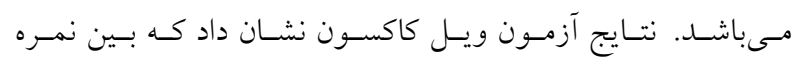
خودمراقبتى در حيطه سـلامت عمـومى يسيش از مشـاوره بـا نمــره خــودمر اقبتى در حيطـه مـذكور يـك مــاه بعـداز مشـاوره تفــاوت

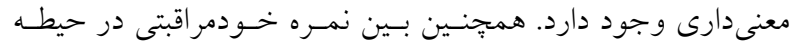

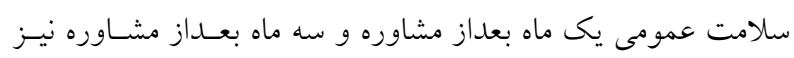

$$
\text { تفاوت معنى دارى مشاهده گرديد. }
$$

همجنين 1 نفر (19 \%) از آنها در طى 9 مـاه گذشسته در مراكـز بهاشتى درمانى تحت معاينه سينه قـرار گرفتـهانـــ. طـى r-r سـال

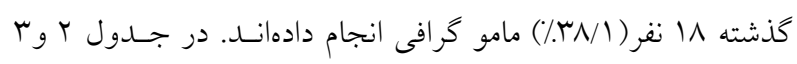
توزيـع فراوانسى واحسـدهاى يـزَوهش برحسـب وضسعيت سـلامت،

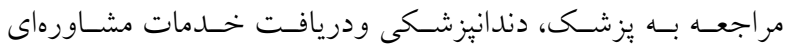
مشاهله مي شود.

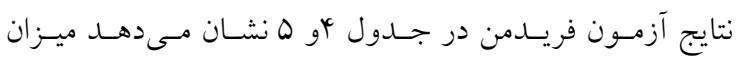

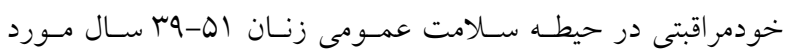
يُزوهش يس از مشاوره بصورت معنى دارى تغيير كرده است. مقايسه

جدول ب: توزيع فراو انى واحدهاى بزوهش بر حسب ارزيابى وضعيت سلامت و معاينه يزشكى و مراجعه به دندانيزشك

\begin{tabular}{|c|c|c|c|}
\hline 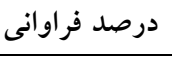 & 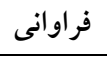 & & متغير \\
\hline $14 / \pi$ & 9 & ضعيف & وضعيت سلامت خود را پخونه ارزيابى مىكنيد؟ \\
\hline $99 / 0$ & ro & متوسط & \\
\hline$r \& / r$ & 11 & خوب & \\
\hline$r \Delta / \mathrm{V}$ & 10 & خير & آيا براى معاينات يزشكى(جى آب) به يزشك مراجعه مى كنيد؟ \\
\hline $94 / r$ & TV & بله & \\
\hline$\mu / \mu$ & if & خير & آيا شما در يك سال اخير به دندانيزشك مراجعه كرده ايد؟ \\
\hline $99 / \mathrm{N}$ & \山 & بله & \\
\hline$\Delta Q / r$ & $\wedge$ & 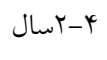 & آخرين بارى كه به دندان يزشك مراجعه كرده ايـــ جــه مـــت قبـل بـوده \\
\hline$\kappa \psi / \Lambda$ & 4 & 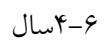 & است؟ \\
\hline
\end{tabular}


جدول r: توزيع فراوانى واحدهاى يزوهش برحسب مشاوره تغذيه و فعاليت بدنى و نشانهاى يائسخى و موضوعات جنسى

\begin{tabular}{|c|c|c|c|}
\hline درصد فراوانى & 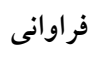 & & متغير \\
\hline $94 / 4$ & TV & خير & آيا تا به حال در خصوص تغذيه مورد مشاوره قرار كَرفته ايد؟ \\
\hline$r \Delta / \mathrm{r}$ & 10 & بله & \\
\hline$\wedge 1$ & ry & خير & آيا تا به حال در خصوص فعاليت بدنى مورد مشاوره قرار كرفته ايد؟ \\
\hline 19 & $\wedge$ & بله & \\
\hline $9 \cdot / 0$ & ґ^ & خير & آيا تا به حال در خصوص نشانهاى (علائم )يائسكى مورد مشاوره قرار كَرفته ايد؟ \\
\hline $9 / 0$ & r & بله & \\
\hline 1.. & kr & خير & آيا تا به حال در خصوص موضوعات جنسى مورد مشاوره قرار كرفته ايد؟ \\
\hline . & . & بله & \\
\hline
\end{tabular}

جدول با: ميانگين و انحراف استاندارد سه بار اندازه كيرى نمره متغير خودمراقبتى

\begin{tabular}{|c|c|c|c|c|c|c|}
\hline \multicolumn{2}{|c|}{ 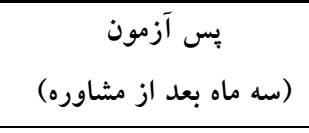 } & \multicolumn{2}{|c|}{ 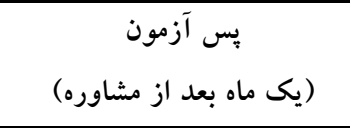 } & \multicolumn{2}{|c|}{ 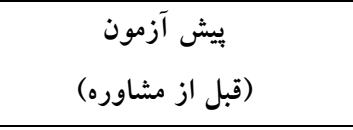 } & \multirow{2}{*}{ ختودمر اقبتى درحيطه سلامت عمومى } \\
\hline انحر اف معيار & ميانكين & انحر اف معيار & ميانكين & انحر اف معيار & ميانكين & \\
\hline 10/VA & Q1/QH & $10 /{ }^{\infty} Q$ & $k 9 / 94$ & $19 / 01$ & $\mu \cdot / \mu 1$ & \\
\hline
\end{tabular}

جدوله: نتايج آزمون تحليل واريانس دوطرفه فريدمن

\begin{tabular}{|c|c|c|c|c|c|}
\hline معنى دارى سطح & درجه آزادى & خى دو & \multicolumn{2}{|c|}{ ميانكين رتبه } & متغير \\
\hline \multirow[t]{3}{*}{$\cdot \cdots \cdot$} & r & $V Q / V Q D$ & $1 / \cdot 4$ & ييش از مشاوره & خودمر اقبتى درحيطه \\
\hline & & & $r / \cdot 9$ & يكى ماه بعد & سلامت عمومى \\
\hline & & & $r / q$. & سه ماه بعد & \\
\hline
\end{tabular}

سلامت عمومى مربوط به سه ماه هـس ازمشاوره مسىباشـــ نتـايج

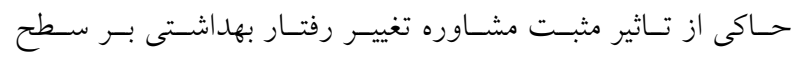
خودمراقبتى درحيطه سلامت عمومى مى باشد.

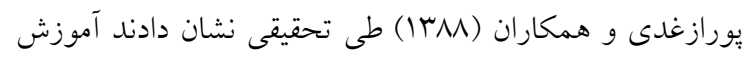

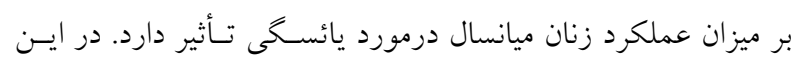

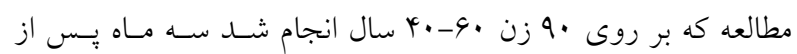

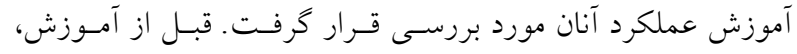

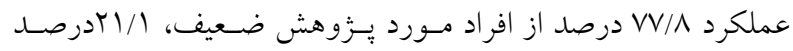
نتايج بدست آمده نشان داد كه مشاوره مبتنى بر خودمراقبتى بـر رفتار زنان حول وحوش يائسكى درحيطه سـامت عمـومى(شـامل

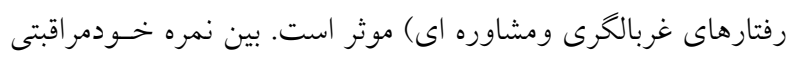

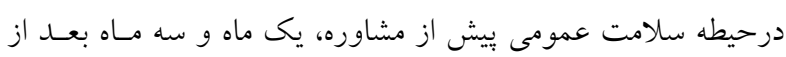

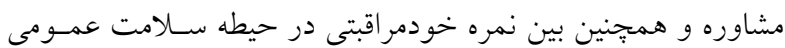

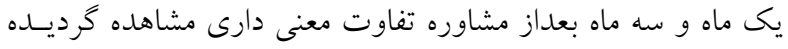

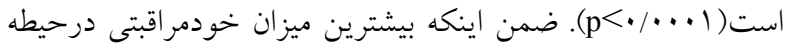




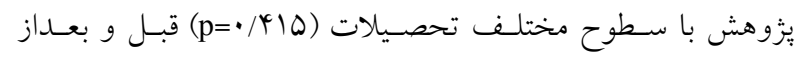

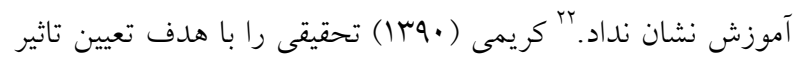

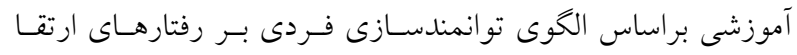

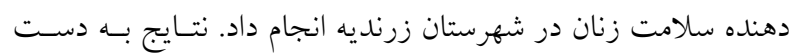

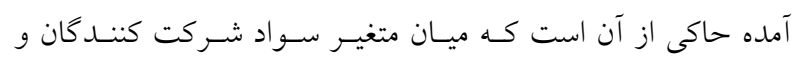

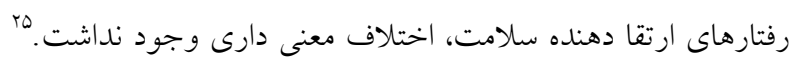
هم جنين قربانى و همكاران (9011)، دريزوهشى نشان دادند كه بين

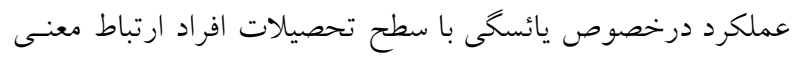

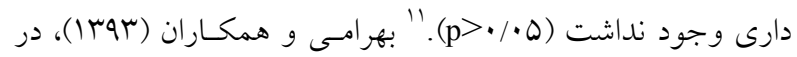
يك مطالعه توصيفى تحليلى در دزفول، تحت عنوان "ارتباط عو امـل

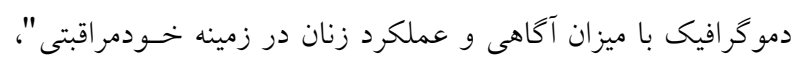

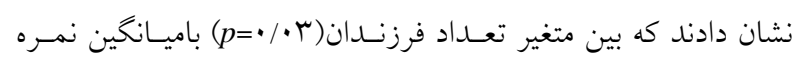

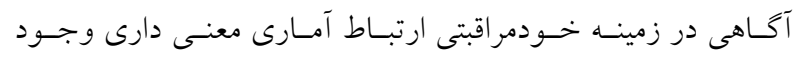

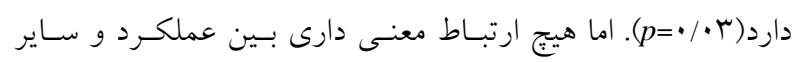
عوامل دموكرافيك در مطالعه آنان ديده نشد. 19

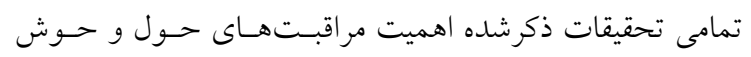

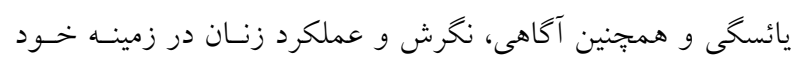

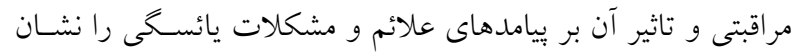
مىدهند. مطالعات ايرانى انجام شده در مورد آكاهى، نخرش، تعيسين و ارتقاى سطح خود مراقبتى بيشتر به صسورت آمـوزش و در زنـان

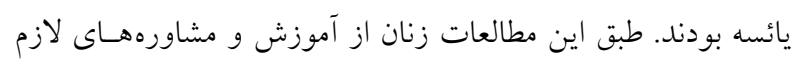

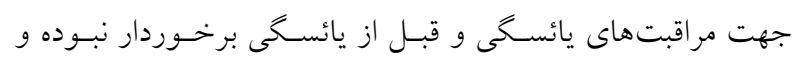

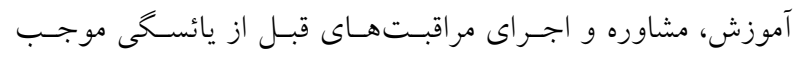

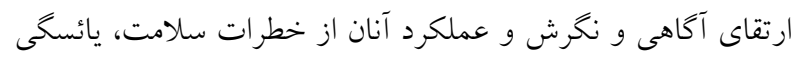
و قبل از يائسخى، سلامت كلى و كيفيت زندگى آنان مىشود. نتـايج اين مطالعه اثربخشى مشاوره تغيير رفتار بهداشتى را كه بـا تكيـه بــر

سطح خودمراقبتى هر فرد طراحى گرديده است بارزتر مى نمايد.

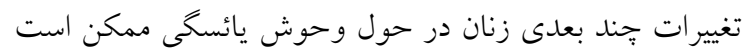

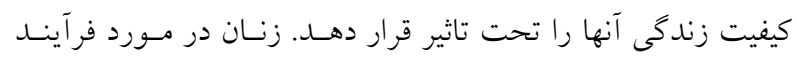

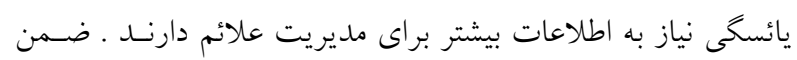

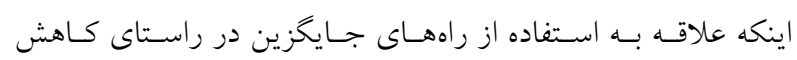

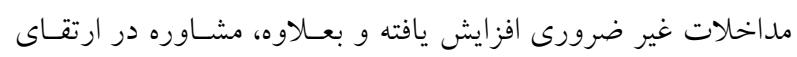

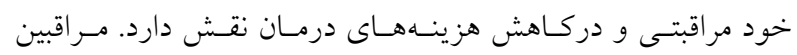
بهداشتى به خصوص ماماها و مشاوران در حيطه مامايى بايستى بـــ
متوسط و فقط // ادرصد عملكردخوب داشتند، درصورتى كه بعـد

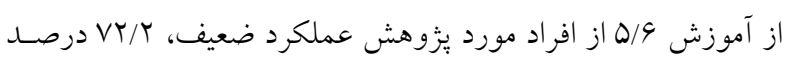

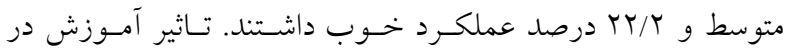

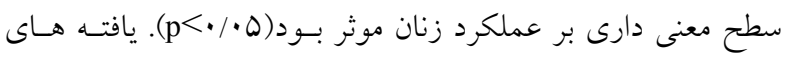

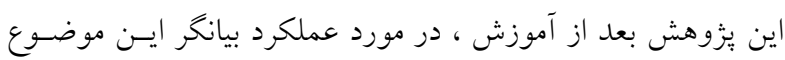

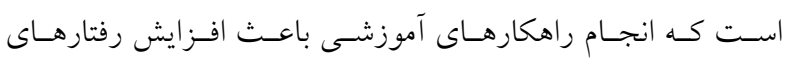

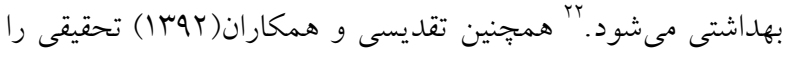

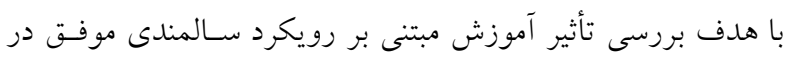

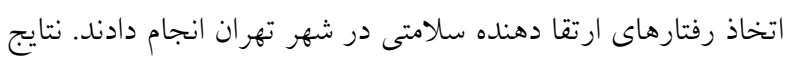
نشان داد نمره كل رفتارهاى ارتقادهنده سلامتى گروه مداخله يس از مداخله آموزشى افزايش قابل توجه داشته كه نشاندهنده تاثير برنامسه دئه

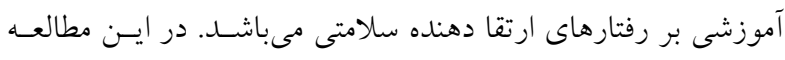

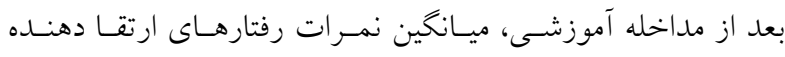

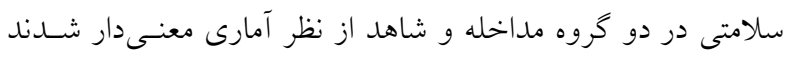

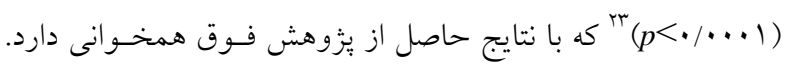

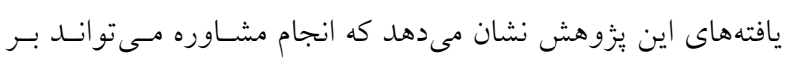

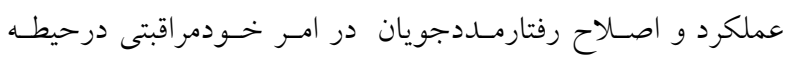

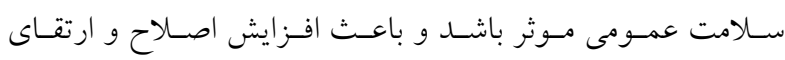
رفتارهاى بهداشتى در آنان شود.

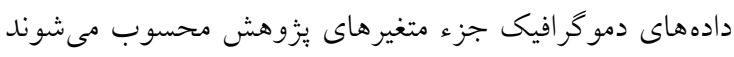
و عبارتند از مشخصات واحدهاى يزّوهش كه مورد توجـه محققسين بوده و در اغلب مطالعات اندازه گيرى مىشوند. با توجسه بـه نتـايج بدست آمده از يزوهش حاضر بر اساس آزمون كروسـكال والسيس ، ميانگين افزايش نمره خودمراقبتى با سطح تحصيلات، تعداد فرزندان

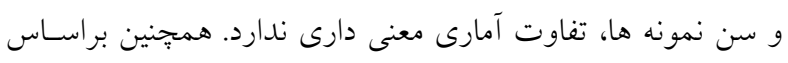

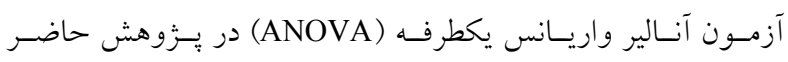

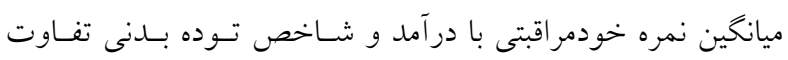
آمارى معنى دارى نداشته كه بـا تحقيـق كليـان تهرانسى و همكــاران

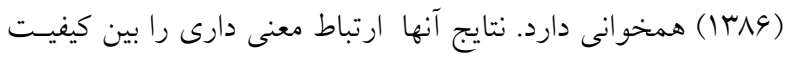
زندگى با تحصيلات و وضعيت اقتصادى نشان نداد. بَ شيخى زاده و

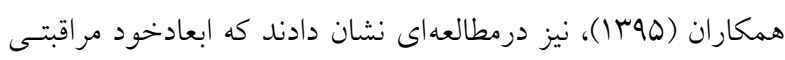

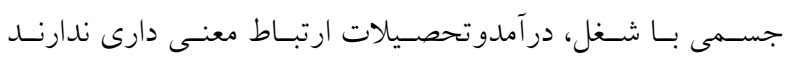

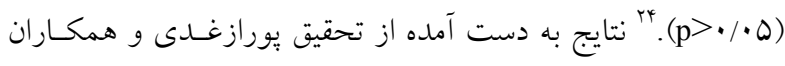

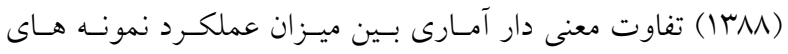


مىباشند. يافته هاى اين يزٔوهش مىتواند بـهـ عنـوان نقطـه شـروعى

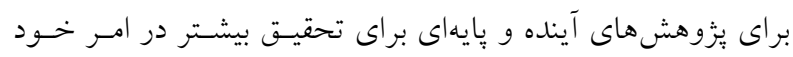
مراقبتى زنان باشد.

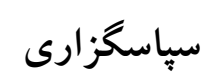

محققان بدين وسيله تشكر خـود را از دانشـاه علسوم بزشـكى

البـرز وهمكـارى معاونـت يزٔوهشى در انجـام ايسن تحقيـق اعـلام

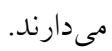

\section{References}

1. Sharifi N, Jalili L, Najar S, Yazdizadeh H, Haghighizadeh MH. Survey of general health and related factors in menopausal women in Ahvaz city، 2012. Razi Journal of Medical Sciences. 2015;21(128):59-65. [In Persian ]

2. Tiznobaic A. The effects of the counseling on life style of menopausal women and theirhusbands[dissertation]. Tehran University of Medical Sciences. 2008:164p.[In Persian ]

3. Berek Js, Novak E. In: Ghazi jahan B، ghotby R.Berek \& Novak's Gynecology. Tehran: golban; 2012.[In Persian]

4. Anjaly N, Viswanath L, Philip TA. Assess the Knowledge on Menopausal Self-care among Perimenopausal Women. Journal of SAFOMS. 2014;2(2):55

5. Speroff L, Fritz MA. In: Ghazi jahan B، ghotby R. Clinical gynecologic endocrinology and infertility. Tehran: golban; 2011.[In Persian]

6. Jami Abedmokhadam Z, Bijeh N, Hashemi Gavaheri A. The effect of aerobic exercise on menopausal symptoms and quality of life in non- athlete postmenopausal women. Journal of Urmia Nursing and Midwifery Faculty. 2014;12(3):173-82. [In Persian]

7. Population census of IRAN. Statistical Center of Iran. 2011.

8. Yazdkhasti M, Simbar M, Abdi F. Empowerment and coping strategies in menopause women: a review. Iranian Red Crescent Medical Journal. 2015;17(3).

9. Moghimi Hanjan s, Shoghi m, Shahbazi A. Quality of life in menopausal stage of women in karaj health center. Journal of health psychology. 2011;1(3):135-50.[In

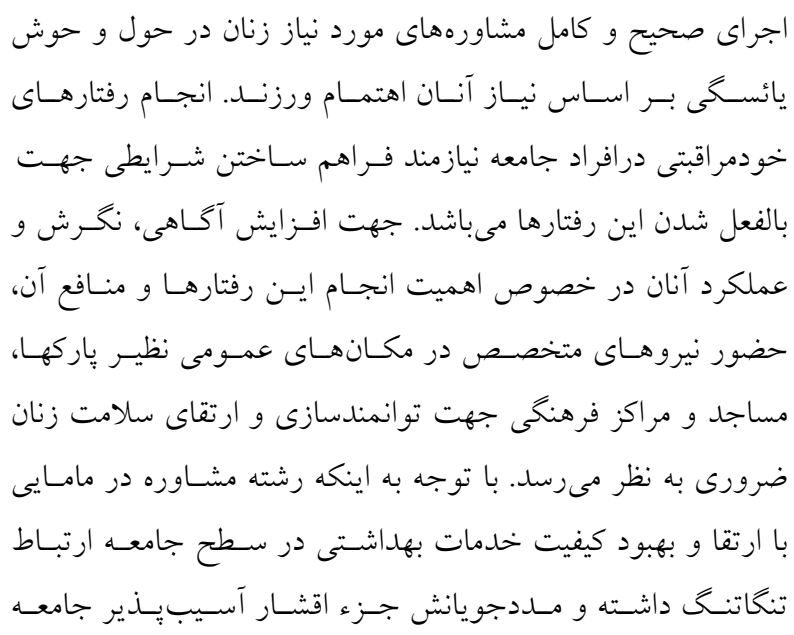

Persian]

10. Nazarpour S, Simbar M, RamezaniTF. Factors affecting sexual function during menopause: a review of the literature. Payesh. 2015;1:41-58.[In Persian ]

11. Ghorbani R, Bahrami Tabar S, Shahbazi A, Alizadeh A. Knowledge and Performance of 45-60 Years Old Women about Health-related Issues of Menopause in Semnan, Iran, 2012. The Iranian Journal of Obstetrics, Gynecology and Infertility. 2013;16(73):1-8.[In Persian]

12. Lee P-S, Tsao L-I, Liu C-Y, Lee C-L. Effectiveness of Telephone-Based Counseling for Improving the Quality of Life Among Middle-Aged Women. Health care for women international. 2014;35(1):74-86.

13. Doubova SV, Espinosa-Alarcón P, Flores-Hernández S, Infante C, Pérez-Cuevas R. Integrative health care model for climacteric stage women: design of the intervention. BMC women's health. 2011;11(1):6.

14. Nikkhah P, Abedi P, Najjar S. The Effect of Walking with Pedometer on General Health of Postmenopausal Women. The Iranian Journal of Obstetrics، Gynecology and Infertility. 2015;18(141):8-17.[In Persian]

15. Golshiri P, Sadri G, Farajzadegan Z, Sahafi M, Najimi A. Is There Any Association between Family Function Self Care in Women? Journal of Isfahan Medical School. 2012;29(166):[In Persian]

16. Mirkarimi SK, Aryaie M, Kamran A, Farid H. Knowledge, attitude and practice of women referred to health centers of Gorgan on the determining factors of self-care. jorjani. 2014;2(2):58-0 .[In Persian]

17. Khaledian Z. Quality of life in terms of different stages of menopause among women in Tehran [MSc Thesis]. 
Tehran: Tehran University of Medical Sciences; 2001.[In Persian]

18. Iioka $Y$, Komatsu $H$. Effectiveness of a stress management program to enhance perimenopausal women's ability to cope with stress. Japan Journal of Nursing Science. 2015;12(1):1-17.

19. Bahrami N, Pajouhideh Z, Mohammadi SKS, Maraghi E. Attitude and Practice towards Self-care in Women Referred to Health Centers in Dezful. Community Health 2015;2(1):50-6.[In Persian]

20. Jafary F, Farahbakhsh K, Shafiabadi A, Delavar A. Quality of life and menopause: Developing a theoretical model based on meaning in life، self-efficacy beliefs، and body image. Aging \& mental health. 2011;15(5):630-7.

21. Golyan Tehrani S, Mir Mohammad Ali M, Mahmoudi M, Khaledian Z. Study of quality of life and its patterns in different stages of menopause for women in Tehran.
Journal of hayat. 2002;8(3):33-41.[In Persian]

22. Hasan PAB, Abbasi Z. Effect of education on middleaged women's knowledge and attitude towards menopause in Mashhad. J Birjand Univ Med Sci. 2006;13:48-54.

23. Estebsari F, Taghdisi MH, Foroushani AR, Ardebili HE, Shojaeizadeh D. An educational program based on the successful aging approach on health-promoting behaviors in the elderly: a clinical trial study. Iranian Red Crescent Medical Journal. 2014;16(4).

24. Sheikhizade S, Ahmadipour H. Self-care activities among women referred to health care centers in Kerman. HealthBased Research .2016;2(1):55-67.[In Persian]

25. Karimy $\mathrm{m}$. Evaluation of the effect of educational intervention based on empowerment model of health promotion behaviors on menopautic women. Daneshvar Scientific-Research Journal of Shahed University 2011;18(94):73-80.[In Persian] 